\title{
Influence of bioadhesive polymers on the protective effect of fluoride against erosion
}

\author{
Daniele Mara da Silva Ávila ${ }^{a}$, Rayssa Ferreira Zanatta ${ }^{a}$, Tais Scaramucci ${ }^{\mathrm{b}}$, \\ Idalina Vieira Aoki ${ }^{\mathrm{c}}$, Carlos Rocha Gomes Torres ${ }^{\mathrm{a}}$, Alessandra Bühler Borges ${ }^{\mathrm{a}, *}$ \\ a Department of Restorative Dentistry, Institute of Science and Technology, São Paulo State University-UNESP, São Paulo, Brazil \\ ${ }^{\mathrm{b}}$ Department of Restorative Dentistry, São Paulo University-USP, São Paulo, Brazil \\ ${ }^{\mathrm{c}}$ Department of Chemical Engineering, Polytechnic School, São Paulo University-USP, São Paulo, Brazil
}

\section{A R T I C L E I N F O}

\section{Article history:}

Received 15 August 2016

Received in revised form 21 October 2016

Accepted 24 October 2016

\section{Keywords:}

Dental erosion

Microhardness

Profilometry

Enamel

Fluoride

Polymers

\begin{abstract}
A B S T R A C T
Objective: This study investigated if the incorporation of the bioadhesive polymers Carbopol 980, Carboxymethyl cellulose (CMC), and Aristoflex AVC in a fluoridated solution (NaF-900 ppm) would increase the solution's protective effect against enamel erosion.

Methods: Enamel specimens were submitted to a 5-day de-remineralization cycling model, consisting of 2 min immersions in $0.3 \%$ citric acid (6x/day), 1 min treatments with the polymers (associated or not with fluoride), and $60 \mathrm{~min}$ storage in artificial saliva. Ultrapure water was used as the negative control and a $900 \mathrm{ppm}$ fluoride solution as positive control. The initial Knoop microhardness (KHN1) was used to randomize the samples into groups. Another two microhardness assessments were performed after the first (KHN2) and second (KHN3) acid immersions, to determine initial erosion in the first day. The formula: \% $\mathrm{KHN}_{\mathrm{alt}}=[(\mathrm{KHN} 3-\mathrm{KHN} 2) / \mathrm{KHN} 2]^{*} 100$ was used to define the protective effect of the treatments. After the 5-day cycling, surface loss (SL, in $\mu \mathrm{m}$ ) was evaluated with profilometry. Data were analyzed with 2-way ANOVA and Tukey's tests $(\mathrm{p}<0.05)$.

Results: For \% $\mathrm{KHN}_{\text {alt }}$, the polymers alone did not reduce enamel demineralization when compared to the negative control, but Carbopol associated with NaF significantly improved its protective effect. The profilometric analysis showed that Carbopol, associated or not with NaF, exhibited the lowest SL, while CMC and Aristoflex did not exhibit a protective effect, nor were they able to improve the protection of NaF. Conclusions: It is concluded that Carbopol enhanced NaF's protection against initial erosion. Carbopol alone or associated with $\mathrm{NaF}$ was able to reduce SL after several erosive challenges.

Clinical significance: Carbopol by itself was able to reduce the erosive wear magnitude to the same extent as the sodium fluoride, therefore, is a promising agent to prevent or control enamel erosion.
\end{abstract}

(c) 2016 Elsevier Ltd. All rights reserved.

\section{Introduction}

Dental erosion can be described as a loss of tooth minerals due to chemical dissolution, which occurs by intrinsic or extrinsic acids in the absence of microorganisms. Clinically, the initial sign of the erosive process in enamel is the appearance of a smooth and silkglazed surface. Later, convex areas become flat, shallow concavities

\footnotetext{
* Corresponding author at: Department of Restorative Dentistry, Institute of Science and Technology, São Paulo State University-UNESP, Avenida Engenheiro Francisco José Longo, 777, Jardim São Dimas, São José dos Campos, SP, ZIP code: 12245-000, Brazil.

E-mail addresses: daniele.avila@ict.unesp.br (D.M.d.S. Ávila), rayssa.zanatta@ict.unesp.br (R.F. Zanatta), tais.sca@usp.br (T. Scaramucci), idavaoki@usp.br (I.V. Aoki), carlosrgt@ict.unesp.br (C.R.G. Torres), alessandra@ict.unesp.br, alebuhler@gmail.com (A.B. Borges).
}

start to appear, the cusps become rounded, and restorations seem to rise above the adjacent tooth level [1]. In more severe cases, the tooth can lose its entire morphology, resulting in unpleasant consequences, such as loss of vertical dimension and sensitivity [2].

The prevention of the erosive process and, consequently, the arrestment of the erosive lesions, can be influenced by several factors, including the exposure of the tooth to fluoride or other protective/remineralizing agents. The effectiveness of sodium fluoride $(\mathrm{NaF})$ against dental erosion has been extensively investigated [3-5]. Up until now, there was an indication of some anti-erosive effect [6,7], albeit in a limited way, possibly due to the high dissolution of calcium fluoride deposits under high acidic erosive conditions $[4,8]$. In addition, fluoride does not present high substantivity in the oral cavity, especially when delivered in 
vehicles for daily application, such as mouth rinses and dentifrices [9].

In order to remain at therapeutic levels and effectively act in the oral environment, fluoride and any other active agent must withstand salivary clearance and the sheer forces associated with speaking, swallowing, and eating [10]. To increase the bioavailability of drugs and actives in oral products, some bioadhesive polymers have been investigated. These polymers can potentially enhance the retention of actives within the oral cavity, improving their residence time $[10,11]$. Nevertheless, studies investigating the addition of the bioadhesive polymers to fluoride-containing solutions are scarce. So far there is some evidence that these bioadhesive agents can influence the adsorption of fluoride, thereby enhancing its protective effect against erosion [12], but more studies are needed to confirm this fact.

In addition to their bioadhesive properties, some polymers also have the ability to form films over the dental surfaces, thus reducing the ionic exchange between the acid solution and the dental substrate $[13,14]$. These polymers have already been tested as supplements of acidic beverages, in order to reduce their erosive potential [14,15], and as active ingredients in oral rinse solutions or toothpastes [16-19].

Considering the potential of some bioadhesive polymers to increase the substantivity of fluoride in the oral cavity and to create dental protective films, the objectives of this study were as follows: 1. To evaluate whether the incorporation of bioadhesive polymers in a fluoridated solution would increase the interaction of fluoride with the enamel surface, and consequently, its protection against enamel erosion; and 2 . To verify if the bioadhesive polymers tested have the ability to form acid-resistance films over the enamel surface, exerting an anti-erosive effect. The null hypothesis is that the polymers tested, associated or not with $\mathrm{NaF}$, will not present a protective effect against enamel erosion.

\section{Materials and methods}

\subsection{Experimental design}

This study tested two experimental factors: the polymer treatment with four levels (control- ultrapure water, Carbopol 980, Carboxymethyl cellulose (CMC), and Aristoflex AVC) and the presence (or not) of sodium fluoride, both in an erosionremineralization cycling model using bovine enamel specimens $(n=104)$. The response variables were surface microhardness $(\mathrm{KHN})$ for initial erosion analysis, and surface loss $(\mu \mathrm{m})$, the latter measured by stylus profilometry at the end of the cycling (after 5 days).

\subsection{Specimen preparation}

Fresh, non-damaged bovine incisors were collected for this study. The crowns were separated from the roots and stored in $0.1 \%$ thymol solution at $4{ }^{\circ} \mathrm{C}$ until required. One hundred four cylindrical enamel specimens ( $3 \mathrm{~mm}$ in diameter and $2.1 \mathrm{~mm}$ in height) were obtained from the labial surface using a custom-made diamondcoated trephine mill adapted to a circular cutting machine. The specimens were embedded in acrylic resin (ExtecFast Cure Acrylic, ExtecCorp, Enfield, CT, USA) using a silicone mold, which consisted of a cavity with $2 \mathrm{~mm}$ deep and $6 \mathrm{~mm}$ in diameter. Also, in the bottom of the mold there was a second level cavity with a $0.1 \mathrm{~mm}$ deep and $3 \mathrm{~mm}$ in diameter, in which the specimens were positioned with the enamel surface facing down [20]. On the lower side of the mold there was a projection in the shape of a line, which produced a lateral notch in the specimen. This allowed the exact repositioning of the specimen at the time of the surface profile measurement (before and after testing).
After the resin cure, the specimens were attached to a metal holder, and the $0.1 \mathrm{~mm}$ high enamel surface was removed and ground flat using aluminum oxide abrasive papers in sequential grits of 1200, 2400, and 4000 (FEPA-P, Struers, Ballerup, Denmark), in a polishing device (DP-10, Panambra Industrial e Técnica SA, São Paulo, SP, Brazil) under water irrigation for 30, 60 and $120 \mathrm{~s}$, respectively. After each paper grit change, specimens were kept in ultrasonic baths in distilled water for $10 \mathrm{~min}$ to remove waste and abrasive grains. The prepared specimens were examined under a stereomicroscope (Carl Zeiss-Stemi 2000 -20X) to ensure the absence of cracks or other surface defects. After preparation, the specimens were stored in ultrapure water at $4{ }^{\circ} \mathrm{C}$ to avoid dehydration.

The initial microhardness (KHN1) of all specimens was assessed using a Knoop Microhardness Tested (FM-700, Future-Tech, Tokyo, Japan) fitted with a $50 \mathrm{~g}$ load, for $10 \mathrm{~s}$. Three indentations were performed, $100 \mu \mathrm{m}$ apart from each other. The recorded values were averaged, and the baseline mean value obtained from all samples was $325.4( \pm 18.5)$. The samples presenting variation in $10 \%$ of the mean were replaced.

Specimens were randomly divided into eight groups $(n=13)$, according to the type of polymer used: Carbopol 980 (Noveon, Cleveland, OH, USA), Carboxymethyl Cellulose (CMC-Synth, Diadema, São Paulo, Brazil), and Aristoflex AVC (PharmaSpecial, Santana de Parnaiba, São Paulo, Brazil), associated or not with 900 ppm sodium fluoride (Synth, Diadema, Sao Paulo, Brazil). The control groups were ultrapure water (negative control) and a 900 ppm fluoride solution (positive control).

\subsection{Preparation of the solutions}

The concentration of the polymers used in this study was determined based on their effect in the viscosity of the solutions, which was intended to simulate a mouth rinse. Several preliminary studies were conducted to determine the highest amount of the polymers that could be added, without interfering with the solutions viscosity. Since Carbopol presented the ability to turn the solution into a gel at lower concentrations, the highest possible concentration determined for this polymer was used as standard for the other polymers, preventing that the concentration was a potential confusing factor.

Finally, the solutions were prepared dissolving $0.1 \mathrm{~g}$ of the polymer in $100 \mathrm{ml}$ of distilled water, in a temperature-controlled environment $\left(25^{\circ} \mathrm{C} \pm 1{ }^{\circ} \mathrm{C}\right)$ to avoid alterations in their kinematic viscosity. To achieve homogeneous solutions, they were placed inside a mixer (SpeedMixer-FlackTek, Landrun, SC, USA) programed at $1500 \mathrm{rpm}$ for $10 \mathrm{~min}$. In the groups containing NaF, $0.2 \mathrm{~g} /$ $100 \mathrm{ml}(900 \mathrm{ppm})$ was added to the solutions.

The $\mathrm{pH}$ of all solutions was adjusted to 4.5. This low $\mathrm{pH}$ was used to favor the deposition of CaF2-like globular structures on dental surface [21]. In addition, this acidic $\mathrm{pH}$ helped the maintenance of the low viscosity of the solutions. The solutions using Carbopol presented pH values lower than 4.5 , therefore $0.1 \mathrm{M}$ $\mathrm{KOH}$ solution was used to increase their $\mathrm{pH}$ to 4.5. The Aristoflex and $\mathrm{CMC}$ solutions presented a natural $\mathrm{pH}$ between 6.1 and 6.7, so $\mathrm{HCl}$ was used to decrease their $\mathrm{pH}$ to 4.5 .

For the viscosity measurements, a kinematic viscometer (TV2000AKV, Tamson Instruments, Bleiswijk, Netherlands), using a Cannon-Fenske glass tube number 100 was used, at $36^{\circ} \mathrm{C}$. Kinematic viscosity was measured by the time taken for the fluid to flow through a capillary tube under the gravity force at a given temperature and was converted directly to a kinematic viscosity using a simple calibration constant provided for each tube. Different sized capillaries were available to support fluids of different viscosities. The unit of kinematic viscosity is centistoke (cSt) (Table 1). 
Table 1

Initial $\mathrm{pH}$, mean of cinematic viscosity (cSt) after $\mathrm{pH}$ adjustment for 4.5 for all treatment solutions tested.

\begin{tabular}{lll}
\hline Solutions & Initial pH & Viscosity cSt $\left(36^{\circ} \mathrm{C}\right)$ \\
\hline NaF $(900 \mathrm{ppm} \mathrm{F})$ & 6.3 & 0.79 \\
Aristoflex $+\mathrm{NaF}$ & 6.1 & 1.01 \\
Aristoflex & 5.7 & 1.89 \\
Carbopol + NaF & 4.4 & 1.28 \\
Carbopol & 4.2 & 4.92 \\
$\mathrm{CMC}+\mathrm{NaF}$ & 6.4 & 2.49 \\
$\mathrm{CMC}$ & 6.7 & 1.83 \\
\hline
\end{tabular}

\subsection{Erosive challenge and remineralization}

The erosive challenge was performed with a $0.3 \%$ citric acid solution, natural $\mathrm{pH}$ of approximately 2.6 , which was obtained by adding $3 \mathrm{~g} / \mathrm{l}$ of citric acid (Dinâmica, Diadema, São Paulo, Brazil) to $1000 \mathrm{ml}$ of ultrapure water. The challenge consisted of immersing specimens in the citric acid for $2 \mathrm{~min}$, six times a day. Polymer treatment with the test solutions was performed twice a day, after the first and last acid challenges, for $1 \mathrm{~min}$. Between the acid exposures and $30 \mathrm{~min}$ before the polymer treatment, the specimens were stored in artificial saliva for $1 \mathrm{~h}$. Artificial saliva was prepared using the following formula [22]: $22.1 \mathrm{mmol} / 1 \mathrm{NaHCO}_{3}$; $16.1 \mathrm{mmol} / 1 \mathrm{KCl} ; 14.5 \mathrm{mmol} / \mathrm{l} \mathrm{NaCl} ; 2.6 \mathrm{mmol} / 1 \mathrm{KH}_{2} \mathrm{PO}_{4} ; 0.8 \mathrm{mmol} / \mathrm{l}$ $\mathrm{H}_{3} \mathrm{BO}_{3} ; 0.7 \mathrm{mmol} / \mathrm{l} \mathrm{CaCL}{ }_{2}{ }^{*} \mathrm{H}_{2} \mathrm{O} ; 0.4 \mathrm{mmol} / \mathrm{KSCN}$; and $0.2 \mathrm{mmol} / \mathrm{l}$ $\mathrm{MgCl}_{2}{ }^{*} 6 \mathrm{H}_{2} \mathrm{O}$, adjusted to $\mathrm{pH}$ 7.0. The erosive challenge was repeated for 5 days. In the overnight period, the specimens were kept in relative humidity, at $4{ }^{\circ} \mathrm{C}$. Fig. 1 shows a schematic chart illustrating the erosive cycle.

\subsection{Microhardness analysis}

The initial erosion was assessed by means of a microhardness test, with the same parameters previously described, and performed twice: after the first acid challenge (KHN2), and after the second acid challenge (KHN3).

After taking the microhardness measurements, the protective effect of the solutions against the acid challenge was determined by means of the Percentage of Microhardness Alteration (\% $\left.\mathrm{KHN}_{\mathrm{alt}}\right)$, using the formula \% $\mathrm{KHN}_{\mathrm{alt}}=[(\mathrm{KHN} 3-\mathrm{KHN} 2) / \mathrm{KHN} 2]^{*} 100$.

\subsection{Surface loss assessment}

In order to maintain the reference surfaces for lesion-depth determination (profilometry) and to allow exact replacement, two parallel grooves were marked on the sides of the acrylic resin surface to serve as guides. Before the beginning of the erosive challenge, profiles of each specimen were obtained from the enamel surfaces with a contact profilometer (MaxSurf XT 20, Mahr-Goettingen, Germany). The diamond stylus moved from the first reference area in the acrylic resin to the second one $(4.2 \mathrm{~mm}$ long). Three profile measurements were performed for each specimen at intervals of $0.25 \mathrm{~mm}$.

At the end of the cycling ( 5 days), the final profiles were obtained in the same place as the first ones. The specimens were placed in a custom-made setting device in order to allow the exact replacement of the samples after the experimental procedures. Enamel loss was calculated after matching the baseline and postpolymer treatment profiles, using the previously described grooves as guides. The depth of the treated area was calculated based on the subtraction of the two profiles using a dedicated software (MarSurf XCR 20 4.50-07 SP3, 2011).

\section{7. $\mathrm{KOH}$-soluble fluoride determination}

After the profilometric analysis, the amounts of $\mathrm{KOH}$-soluble fluoride from enamel surfaces were determined based on a method described elsewhere [23]. Briefly summarized, the specimens were individually stored in plastic containers with $0.5 \mathrm{ml}$ of $1.0 \mathrm{M} \mathrm{KOH}$ solution, under gentle agitation at room temperature for $24 \mathrm{~h}$. After this period, the specimens were rinsed, and a sample of the solution $(0.25 \mathrm{ml})$ was transferred to a plastic vial and neutralized with $0.25 \mathrm{ml}$ of $1 \mathrm{M} \mathrm{HClO}_{4}$. Then, $0.5 \mathrm{ml}$ of TISAB II buffer was added to the tube. The fluoride content was determined by comparison to a similarly prepared standard curve using an ion-selective electrode (Perfection, Mettler Toledo, Schwerzenbach, Switzerland).

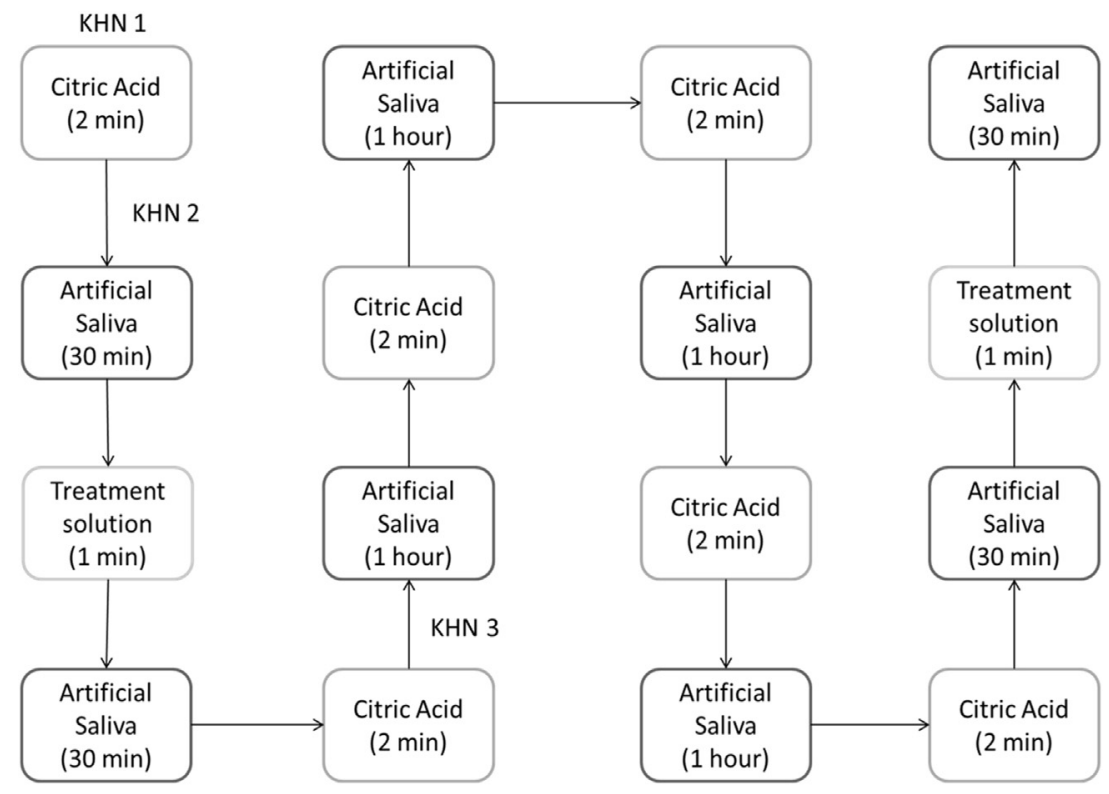

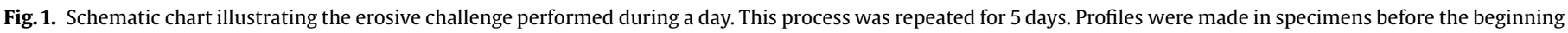
of the erosive challenge, and at the end of the fifth day. KHN1, KHN2 and KHN3 indicate the moments in which microhardness were measured (in the first day). 


\subsection{Energy-dispersive spectroscopy (EDS) and scanning electron microscopy (SEM)}

Additional specimens were prepared, polished, and immersed in $0.3 \%$ citric acid for $10 \mathrm{~min}$. After rinsing, the specimens were treated with the experimental treatment solutions for $1 \mathrm{~min}$ and dehydrated. The specimens were then mounted on aluminum stubs, sputtered with gold (Emitech SC7620 Sputter Coater, Moorestown, NJ, EUA) for $2 \mathrm{~min}$, and taken to the scanning electron microscope (Inspect S50, FEI, Hillsboro, OR, EUA). The images were obtained in secondary electron mode $(15 \mathrm{kV}, 100 \mathrm{~s})$ at $5.000 x$ magnification. The energy-dispersive spectroscopy (EDS) analysis was performed using an EDS-detector coupled at the scanning electron microscope, with spot size at 3.0 and voltage at $10 \mathrm{kV}$. The detector was used to assess the presence of fluoride in each sample. The weight percentage of fluoride was analyzed stoichiometrically.

\subsection{Statistical analysis}

Assumptions of normal distribution (Kolmogorov-Smirnov tests) were checked for all the variables tested. Descriptive and inferential statistical analyses were performed using Minitab 16.1.0 (2010 Minitab, State College, PA, USA) and Graphpad Prism (Graphpad Prism Software, La Jolla, CA, USA). Two-way ANOVA was performed for both profilometry and microhardness analyses, followed by Tukey's test with $5 \%$ significance.

\section{Results}

\subsection{Microhardness analyses}

The values obtained for KHN2 and KHN3 are shown in Fig. 2. The means and standard deviations of the Percentage of Microhardness Alteration $\left(\% \mathrm{KHN}_{\mathrm{alt}}\right)$ for all solutions tested, used in the
Table 2

Mean and SD for Percentage of Microhardness Alteration $\left(\% \mathrm{KHN}_{\mathrm{alt}}=[(\mathrm{KHN} 3-\right.$ KHN2)/KHN2]*100) for the solutions tested. Higher values indicate decreases of microhardness, and therefore worse behavior of the agents.

\begin{tabular}{lll}
\hline Treatment Solutions & $\mathrm{NaF}^{\mathrm{a}}$ \\
\cline { 2 - 3 } & Absence & Presence \\
\hline Aristoflex & $23.21 \pm 8.30 \mathrm{Aa}$ & $17.80 \pm 5.84 \mathrm{Aa}$ \\
CMC & $24.93 \pm 8.61 \mathrm{Aa}$ & $18.22 \pm 8.72 \mathrm{Aa}$ \\
Carbopol & $23.18 \pm 8.60 \mathrm{Aa}$ & $-3.00 \pm 7.34 \mathrm{Bb}$ \\
Water (control) & $23.15 \pm 7.78 \mathrm{Aa}$ & $17.61 \pm 8.10 \mathrm{Aa}$ \\
\hline
\end{tabular}

${ }^{a}$ Uppercase letter show difference in columns and lowercase letters show difference in rows.

statistical analysis, are presented in Table 2. In this analysis, higher values indicate a decrease in microhardness, therefore, a worse behavior of the agents. Two-way ANOVA showed significant differences for the polymer $(\mathrm{p}=0.001)$ and presence of fluoride $(p=0.001)$ factors, as well as for the interaction between them $(p=0.001)$. Tukey's test revealed that in the absence of NaF, all of the polymers had the same performance, but in the presence of $\mathrm{NaF}$, Carbopol was able to promote a significant protection of the enamel surface against initial erosion.

\subsection{Surface loss analysis}

The means and standard deviations of surface loss $(\mu \mathrm{m})$ for all of the polymers tested, associated or not with $\mathrm{NaF}$, are presented in Table 3. The results of 2-way ANOVA showed a significant difference $(p<0.05)$ for all of the factors analyzed: polymer $(p=0.0001)$, presence of fluoride $(p=0.003)$, and the interaction between the two $(\mathrm{p}=0.001)$. When applied to the fluoride factor, Tukey's test revealed that the presence of NaF significantly decreased the mineral loss as compared to its absence. For the polymer factor, Carbopol presented lower values than the other polymers and the control group. Regarding the interaction

\section{Microhardness}

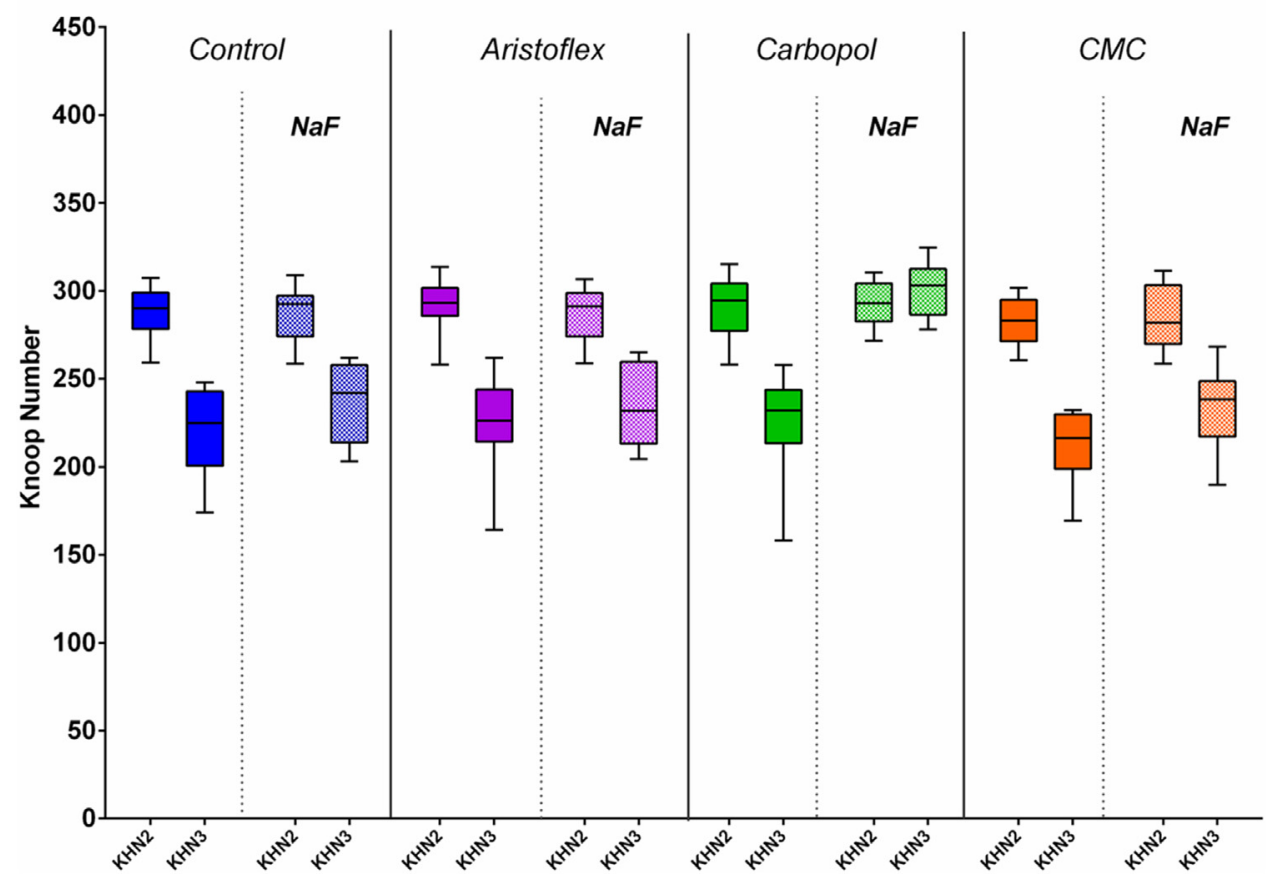

Fig. 2. Box-plot graph of the KHN2 and KHN3 values. 
Table 3

Mean $( \pm \mathrm{SD})$ of surface loss $(\mu \mathrm{m})$ for all polymers tested, associated or not with sodium fluoride $(\mathrm{NaF})$.

\begin{tabular}{lll}
\hline Treatment Solution & $\mathrm{NaF}^{\mathrm{a}}$ \\
\cline { 2 - 3 } & Absence & Presence \\
\hline Aristoflex & $3.13 \pm 0.97 \mathrm{Aa}$ & $2.21 \pm 0.63 \mathrm{Ab}$ \\
CMC & $2.40 \pm 0.48 \mathrm{Aa}$ & $2.87 \pm 0.69 \mathrm{Aa}$ \\
Carbopol & $2.23 \pm 0.63 \mathrm{Ba}$ & $1.80 \pm 0.40 \mathrm{Ba}$ \\
Control (Water) & $3.43 \pm 0.41 \mathrm{Aa}$ & $2.73 \pm 0.81 \mathrm{Ab}$ \\
\hline
\end{tabular}

${ }^{\text {a }}$ Uppercase letter show difference in columns and lowercase letters show difference in rows.

between the polymers and NaF, the results from Tukey's test showed that the Carbopol/NaF association exhibited significantly lower enamel loss than the other conditions tested.

\subsection{Fluoride analysis}

The means and standard deviations of $\mathrm{KOH}$-soluble fluoride $\left(\mu \mathrm{g} / \mathrm{cm}^{2}\right)$ are presented in Table 4 . The results of 2-way ANOVA showed a significant difference for all the elements in the presence of fluoride $(p=0.0001)$. For the polymer factor $(p=0.1078)$ and double interaction $(p=0.6387)$, the differences were not significant. Tukey's test showed that the presence of NaF significantly increased the amount of $\mathrm{KOH}$-soluble fluoride for all solutions.

\subsection{Energy-dispersive spectroscopy analysis}

As expected, EDS analysis (Table 4) revealed the absence of fluoride in the negative control group and in all of the solutions with the polymers alone. The presence of fluoride was detected in all of the groups with $\mathrm{NaF}$.

\subsection{Scanning electron microscopy analysis}

The polymer treatment with the Aristoflex and Carbopol solutions, associated or not with $\mathrm{NaF}$, resulted in the formation of a surface layer covering the enamel prisms. In the CMC group, the eroded prisms were visible, indicating the absence of any protective film. When $\mathrm{CMC}$ was associated with $\mathrm{NaF}$, the eroded pattern was still visible, but with less definition (Fig. 3).

\section{Discussion}

In this study, the null hypothesis had to be rejected, because the bioadhesive polymer Carbopol was able to increase the protective effect of $\mathrm{NaF}$, but only in the initial erosion assessment. At the end of the cycling, Carbopol reduced the magnitude of the enamel loss regardless of the presence of $\mathrm{NaF}$.

Table 4

Mean $( \pm \mathrm{SD})$ of $\mathrm{KOH}$-Soluble Fluoride Determination $\left(\mu \mathrm{g} / \mathrm{cm}^{2}\right)$ and percentages of fluoride (Wt.\%) on enamel surfaces for all solutions tested, associated or not with sodium fluoride $(\mathrm{NaF})$.

\begin{tabular}{|c|c|c|c|c|}
\hline \multirow{2}{*}{$\begin{array}{l}\text { Treatment Solutions } \\
\text { Water (control) }\end{array}$} & \multicolumn{3}{|c|}{$\mathrm{KOH}-$ Soluble Fluoride ${ }^{\mathrm{a}}\left(\mu \mathrm{g} / \mathrm{cm}^{2}\right)$} & \multirow{2}{*}{$\frac{\mathrm{F}[\mathrm{Wt} . \%]}{-}$} \\
\hline & $0.48 \pm 0.45$ & A & & \\
\hline $\mathrm{NaF}$ (control) & $17.55 \pm 5.10$ & & B & 0.22 \\
\hline Aristoflex & $1.81 \pm 0.90$ & A & & - \\
\hline Aristoflex $+\mathrm{NaF}$ & $18.09 \pm 6.21$ & & B & 0.22 \\
\hline Carbopol & $1.66 \pm 0.74$ & A & & - \\
\hline Carbopol + NaF & $20.64 \pm 5.23$ & & B & 0.35 \\
\hline $\mathrm{CMC}$ & $0.68 \pm 1.3$ & A & & - \\
\hline $\mathrm{CMC}+\mathrm{NaF}$ & $16.62 \pm 3.37$ & & B & 0.23 \\
\hline
\end{tabular}

a Uppercase letter show difference in columns.
Carbopol is a high molecular weight polymer of acrylic acid. It is an anionic molecule, which has been used as a thickening agent in many formulations, such as gels, suspensions, and emulsions [24]. In dentistry, Carbopol is commonly added to bleaching gels to increase their viscosity, but its influence on the dental surface is controversial. While some studies have described a reduction in enamel microhardness related to its presence [25-27], there is a report showing no deleterious effect [28]. Besides its eventual acidic $\mathrm{pH}$ (when not properly adjusted), the possible demineralizing effect of Carbopol may be related to its ability to chelate calcium [29]. It can be speculated that such a chelating effect was responsible for the protective effect of Carbopol against erosion demonstrated herein. The authors hypothesized that, since Carbopol is a molecule with many negatively charged centers, it established a bond with the calcium (positively charged centers) from the enamel, thus creating a layer that protected the enamel against dissolution. For the initial erosion, instead of increasing the availability of fluoride, Carbopol acted in combination with fluoride, binding to the calcium sites where fluoride was not bonded. This fact can be corroborated by the $\mathrm{KOH}$-soluble fluoride analysis, where the concentration of fluoride on the surface of the specimens treated with fluoride and Carbopol was not higher than the other groups. At the end of the cycling, the cumulative effect of several Carbopol exposures created a layer of the bioadhesive polymer thick enough to protect the enamel even in the absence of fluoride.

Carboxymethyl cellulose (CMC) is another anionic molecule. It is a polysaccharide frequently used in human saliva substitutes, dentifrices, and other oral hygiene products. There are few studies testing this polymer in erosion research, and they showed that CMC can reduce the hydroxyapatite dissolution [14] as well as the remineralizing effect of artificial saliva [30,31]. The possible mechanism responsible for the reduction in hydroxyapatite dissolution is related to its ability to form film [14]. The reduction in the remineralizing effect of saliva was postulated to be due to a weak bond between CMC and the hydroxyapatite, which acted as a barrier hampering the remineralizing action of saliva. In the present study, at end of cycling CMC showed a tendency (not significant) towards reducing surface loss; nonetheless, since it binds to the surface of the enamel weaker than Carbopol, because its molecule is less negative, the authors speculated that it was more easily removed by the erosive challenge. Perhaps a higher concentration of this bioadhesive polymer would be necessary to show a protective effect. This theory, however, needs to be further investigated.

On the other hand, the other bioadhesive polymer tested, Aristoflex, is a positively charged (cationic) synthetic polysulphonic acid polymer. It is used as a gelling or thickening agent in personal care formulations, and also investigated as a constituent of oral care products, such as whitening toothpastes, mouth rinses, and gels [32,33]. In this study, similar to CMC, it can be suggested that the binding of Aristoflex to the enamel surface was not strong enough to resist the acid challenge; however, at the end of the experiment, the combination of Aristoflex and fluoride tended to reduce surface loss. Although this was not significant, the authors formulated the hypothesis that, as a positive charged molecule, Aristoflex had the ability to attract fluoride ions to interact with its positive sites, aiding, but also preventing, the total beneficial interaction of fluoride with the enamel surface, acting, therefore, as a "competitor" for fluoride interaction with enamel. The $\mathrm{KOH}$-soluble fluoride analysis supports this fact, as a high fluoride amount could not be found at the surface of the enamel specimens treated with Aristoflex and NaF.

The NaF group was able to reduce surface loss at the end of the cycling, but it was not effective in protecting the enamel in the initial erosion assessment. Possibly, the magnitude of the acid 

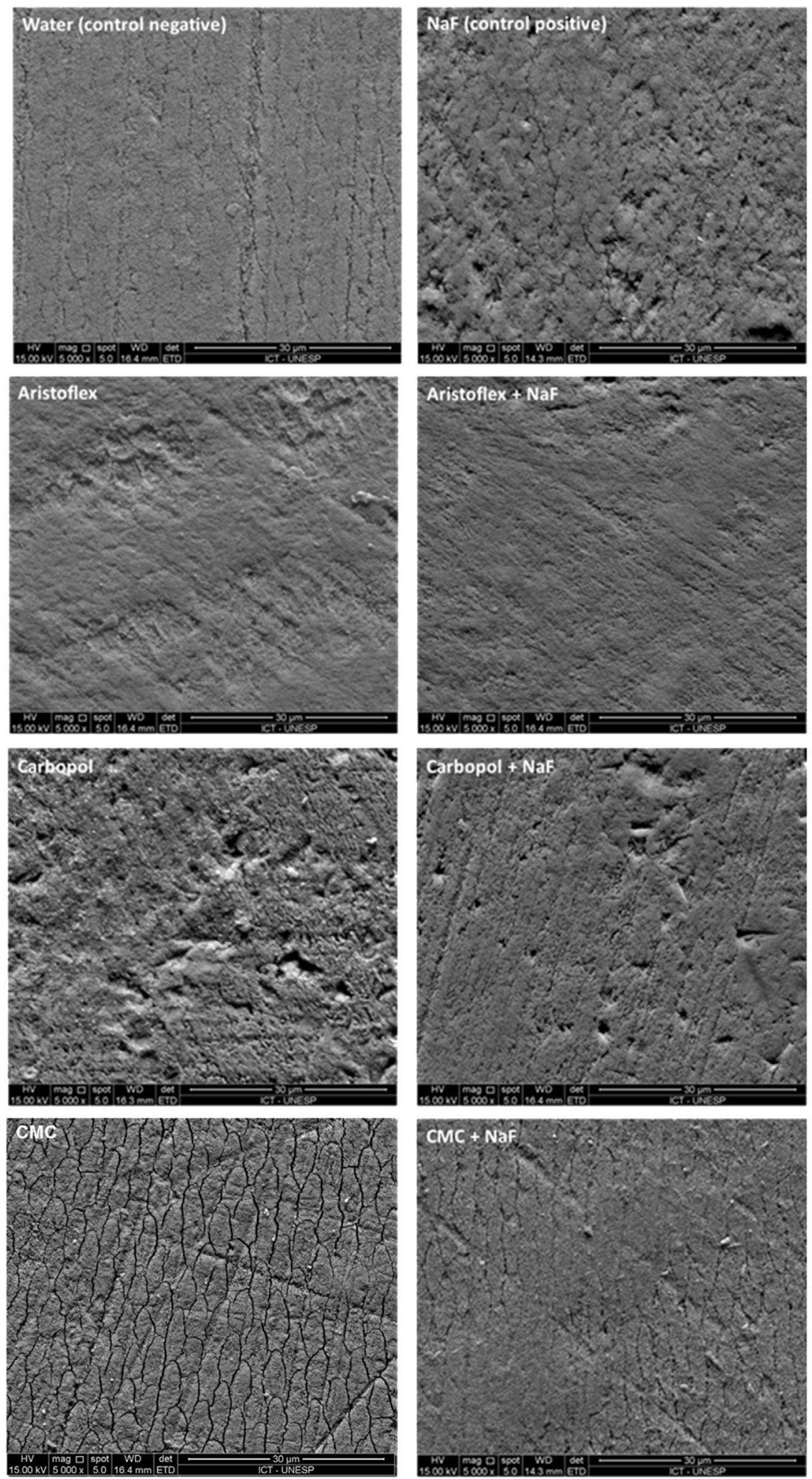

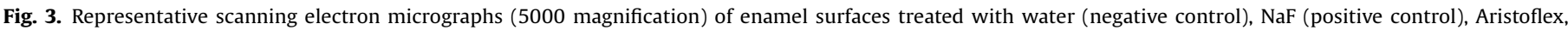
Aristoflex $+\mathrm{NaF}$, Carbopol, Carbopol $+\mathrm{NaF}, \mathrm{CMC}, \mathrm{CMC}+\mathrm{NaF}$.

challenge associated with erosion was so high that a cumulative effect of several $\mathrm{NaF}$ applications is needed to show some protection. The protective role of $\mathrm{NaF}$ in erosion, although limited, is well recognized and thought to be related to the deposition of globular structures similar to calcium fluoride $\left(\mathrm{CaF}_{2}\right)$ on the treated surface. These deposits can act as a physical barrier, reducing the contact between the acid and the underlying tooth mineral [21]. The formation of calcium fluoride-like deposits depends on the concentration, application time, and $\mathrm{pH}$ of the fluoridated formulation [34]. Low $\mathrm{pH}$ values are desirable to favor the fluoride 
deposition. The low $\mathrm{pH}(4.5)$ used in this study was chosen to allow for the formation of $\mathrm{CaF}_{2}$, and also to maintain the solutions with a low viscosity, since CMC and Carbopol can easily increase their viscosity and form a gel with $\mathrm{pH}$ values over 6.0, as was observed in the preliminary tests. It has to be emphasized that the Carbopol solution presented the higher kinematic viscosity, and this may also interfere with the results. Thus, further studies must be conducted to investigate this issue.

The $\mathrm{KOH}$-soluble fluoride analysis showed that the bioadhesive polymers tested were not able to significantly increase the amounts of fluoride at the enamel surface, as was expected. Bioadhesion can be defined as any kind of adhesion phenomenon in which one or more of the involved phases, either the substrate or the adhesive, are part of a living organism, implying the presence of water. This phenomenon occurs by a process of wetting and interpenetration of the bioadhesive polymer with the substrate [24]. In the pharmaceutical industry, it is common to use bioadhesives as delivery vehicles for drugs or substances. Once they increase bioavailability, the bioadhesives allow for the use of lower drug or substance concentrations, and, at the same time, a low contact time between the drug and the surface [24]. Although it is unknown whether the in vivo conditions the bioadhesive polymers are tested in increase fluoride availability in the oral environment, soft oral tissues, and the salivary pellicle, the outcomes of this study suggest that their effect against erosion, if any, was more related to their ability to form film rather than their bioadhesive properties.

In the present study, SEM was used to provide visual information on the precipitates at the enamel surface, as well as to show the changes in the morphology of the surface after the polymer treatment. EDS was used to verify the presence of fluoride on the enamel surfaces. It was not possible to observe globular structures of $\mathrm{CaF}_{2}$-like material in the micrographs (Fig. 3). In the $\mathrm{NaF}$, Carbopol, and Aristoflex associated with NaF groups, the presence of an amorphous layer partially covering the enamel surface can be observed. For the groups treated with CMC, associated or not with $\mathrm{NaF}$, and water group (negative control), the images suggest a demineralization of the periphery of the enamel rods.

This study showed that Carbopol is an interesting agent to be added to oral care products for erosion, since it could reduce surface loss to the same extent as sodium fluoride. However, further investigations are needed to test this agent in a more clinically relevant experimental model, with the presence of salivary pellicle, which has proteins with affinity for the dental surfaces and can potentially influence the anti-erosive effect of film-forming agents.

\section{Conclusion}

Considering the limitations of this in vitro investigation, it could be concluded that Carbopol associated with sodium fluoride was able to reduce initial erosion demineralization. Carbopol by itself reduced the magnitude of the erosive wear to the same extent as sodium fluoride, therefore, it is a promising agent to prevent or control enamel erosion.

\section{Acknowledgements}

The authors do not have any financial interests in the companies whose materials are included in this article. The authors wish to thank CAPES (Coordination of Training of Higher Education Graduate), for the first author's scholarship.

\section{References}

[1] C. Ganss, Is erosive tooth wear an oral disease? Monogr. Oral Sci. 25 (2014) 1621.

[2] N. Schlueter, T. Jaeggi, A. Lussi, Is dental erosion really a problem? Adv. Dent. Res. 24 (2) (2012) 68-71.

[3] A.B. Borges, T. Scaramucci, F. Lippert, D.T. Zero, A.T. Hara, Erosion protection by calcium lactate/sodium fluoride rinses under different salivary flows in vitro, Caries Res. 48 (3) (2014) 93-199.

[4] T. Scaramucci, A.B. Borges, F. Lippert, N.E. Frank, A.T. Hara, Sodium fluoride effect on erosion-abrasion under hyposalivatory simulating conditions, Arch. Oral Biol. 58 (10) (2013) 1457-1463.

[5] S.H. Joao-Souza, S.J. Bezerra, A.B. Borges, A.C. Aranha, T. Scaramucci, Effect of sodium fluoride and stannous chloride associated with Nd:YAG laser irradiation on the progression of enamel erosion, Lasers Med. Sci. 30 (9) (2015) 2227-2232.

[6] C. Ganss, J. Klimek, U. Schaffer, T. Spall, Effectiveness of two fluoridation measures on erosion progression in human enamel and dentine in vitro, Caries Res. 35 (5) (2001) 325-330.

[7] C. Ganss, N. Schlueter, M. Hardt, P. Schattenberg, J. Klimek, Effect of fluoride compounds on enamel erosion in vitro: a comparison of amine, sodium and stannous fluoride, Caries Res. 42 (1) (2008) 2-7.

[8] N. Schlueter, L. Neutard, J. von Hinckeldey, J. Klimek, C. Ganss, Tin and fluoride as anti-erosive agents in enamel and dentine in vitro, Acta Odontol. Scand. 68 (3) (2010) 180-184.

[9] S.C. Mason, S. Shirodaria, F. Sufi, G.D. Rees, D. Birkhed, Evaluation of salivary fluoride retention from a new high fluoride mouthrinse, J. Dent. 38 (Suppl. 3) (2010) S30-6.

[10] M.A. Zaman, G.P. Martin, G.D. Rees, Mucoadhesion, hydration and rheological properties of non-aqueous delivery systems (NADS) for the oral cavity, J. Dent. 36 (5) (2008) 351-359.

[11] M.A. Zaman, G.P. Martin, G.D. Rees, Bioadhesion and retention of non-aqueous delivery systems in a dental hard tissue model, J. Dent. 38 (9) (2010) 757-764.

[12] D. Churchley, G.D. Rees, E. Barbu, T.G. Nevell, J. Tsibouklis, Fluoropolymers as low-surface-energy tooth coatings for oral care, Int. J. Pharm. 352 (1) (2008) 44-49.

[13] M. Beyer, J. Reichert, B.W. Sigusch, D.C. Watts, K.D. Jandt, Morphology and structure of polymer layers protecting dental enamel against erosion, Dent. Mater. 28 (10) (2012) 1089-1097.

[14] M.E. Barbour, R.P. Shellis, D.M. Parker, G.C. Allen, M. Addy, An investigation of some food-approved polymers as agents to inhibit hydroxyapatite dissolution, Eur. J. Oral Sci. 113 (6) (2005) 457-461.

[15] T. Scaramucci, A.T. Hara, D.T. Zero, S.S. Ferreira, I.V. Aoki, M.A. Sobral, In vitro evaluation of the erosive potential of orange juice modified by food additives in enamel and dentine, J. Dent. 39 (12) (2011) 841-848.

[16] T. Scaramucci, S.H. Joao-Souza, F. Lippert, G.J. Eckert, I.V. Aoki, A.T. Hara, Influence of toothbrushing on the antierosive effect of film-forming agents, Caries Res. 50 (2) (2016) 104-110.

[17] N. Schlueter, J. Klimek, C. Ganss, Randomised in situ study on the efficacy of a tin/chitosan toothpaste on erosive-abrasive enamel loss, Caries Res. 47 (6) (2013) 574-581.

[18] N.V. Cruz, J.P. Pessan, M.M. Manarelli, M.D. Souza, A.C. Delbem, In vitro effect of low-fluoride toothpastes containing sodium trimetaphosphate on enamel erosion, Arch. Oral Biol. 60 (9) (2015) 1231-1236.

[19] T. Scaramucci, A.B. Borges, F. Lippert, D.T. Zero, I.V. Aoki, A.T. Hara, Anti-erosive properties of solutions containing fluoride and different film-forming agents, J. Dent. 43 (4) (2015) 458-465.

[20] L.F.T.F. Santos, C.R.G. Torres, T.M.F. Caneppele, A.C. Magalhães, A.B. Borges, Effect of home-bleaching gels modified by calcium and/or fluoride and the application of nano-hydroxyapatite paste on in vitro enamel erosion susceptibility, Acta Odontol. Scand. 74 (2) (2016) 121-126.

[21] A.C. Magalhaes, A. Wiegand, D. Rios, M.A. Buzalaf, A. Lussi, Fluoride in dental erosion, Monogr. Oral Sci. 22 (2011) 158-170.

[22] T.N. Gohring, M. Zehnder, B. Sener, P.R. Schmidlin, In vitro microleakage of adhesive-sealed dentin with lactic acid and saliva exposure: a radio-isotope analysis, J. Dent. 32 (3) (2004) 235-240.

[23] V. Caslavska, E.C. Moreno, F. Brudevold, Determination of the calcium fluoride formed from in vitro exposure of human enamel to fluoride solutions, Arch. Oral Biol. 20 (5-6) (1975) 333-339.

[24] G. Bonacucina, S. Martelli, G.F. Palmieri, Rheological, mucoadhesive and release properties of Carbopol gels in hydrophilic cosolvents, Int. J. Pharm. 282 (1-2) (2004) 115-130.

[25] J.A. Rodrigues, G.M. Marchi, G.M. Ambrosano, H.O. Heymann, L.A. Pimenta, Microhardness evaluation of in situ vital bleaching on human dental enamel using a novel study design, Dent. Mater. 21 (11) (2005) 1059-1067.

[26] R.T. Basting, A.L. Rodrigues Junior, M.C. Serra, The effect of $10 \%$ carbamide peroxide, carbopol and/or glycerin on enamel and dentin microhardness, Oper. Dent. 30 (5) (2005) 608-616.

[27] P. Soldani, C.M. Amaral, J.A. Rodrigues, Microhardness evaluation of in situ vital bleaching and thickening agents on human dental enamel, Int. J. Periodontics Restor. Dent. 30 (2) (2010) 203-211.

[28] J.A. Rodrigues, G.P. Oliveira, C.M. Amaral, Effect of thickener agents on dental enamel microhardness submitted to at-home bleaching, Braz. Oral Res. 21 (2) (2007) 170-175. 
[29] T. Chen [inventor], Adhesive dental bleaching compositions containing polyvinylpyrrolidone, Google Patents (2014).

[30] B.T. Amaechi, S.M. Higham, In vitro remineralisation of eroded enamel lesions by saliva, J. Dent. 29 (5) (2001) 371-376.

[31] F.Q. Ionta, F.L. Mendonca, G.C. de Oliveira, C.R. de Alencar, H.M. Honorio, A.C. Magalhaes, D. Rios, In vitro assessment of artificial saliva formulations on initial enamel erosion remineralization, J. Dent. 42 (2) (2014) 175-179.
[32] R.E. Montgomery [inventor], Highly stable oxidizing compositions, Google Patents (2011).

[33] S. Golding, A.P. Jarvis, A. Joiner, C.J. Philpotts, J. Whittaker [inventor], Oral care compositions, Google Patents (2014).

[34] M. Petzold, The influence of different fluoride compounds and treatment conditions on dental enamel: a descriptive in vitro study of the $\mathrm{CaF}(2)$ precipitation and microstructure, Caries Res. 35 (Suppl. 1) (2001) 45-51. 